\title{
Look Inside Schizophrenia and Discover Common Sense
}

\author{
J Marques-Teixeira*
}

Professor, Psychiatrist, University of Porto, Portugal

*Corresponding author: I Marques-Teixeira, Professor, Psychiatrist, University of Porto, Portugal

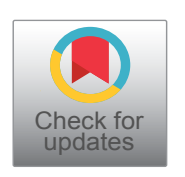

The requirements for a psychopathology of the future settle on the demand of psychiatric science for good explanations of psychiatric illnesses accompanied by an understanding of patients' experiences. This effort, already underway, has focused on the conceptual and practical connection between these two dimensions, translated into the attempt to link the advances in neurobiological explanations and sophisticated understanding of patients' personal and cultural experiences. When considering diagnosis, strategies have been divided between symptomatological approaches, more or less complex, and interpretative approaches, more or less sophisticated.

Due to its complex and heterogeneous nature, schizophrenia has been the center of convergence of this integrative effort of the two types of approach mentioned above. On the one hand, the scientific or explanatory approach to schizophrenia leads us to search for the first cause, the ultimate reason for this strange and bizarre way of being in the world. Much progress has been made in this area, and it is now consensual that schizophrenia is a brain disease, although little is known about the multiple conjugations of the most varied factors that, in fine, end up determining the condition of schizophrenia. Nevertheless, this categorization is fundamental for the implementation of an adequate intervention strategy.

This approach, called objective, says nothing about the individual processes that characterize this particular subject in the path of understanding his way of being in the world that, despite the uniqueness of individual experience, may shed light on the general structure of common experiences. It is the phenomenological analysis that deals not only with the content of the subjective experience but also, and above all, with its structure. Its validation criteria are not the same as those that al- low judgments of objective stories of a scientific nature, such as statistical validity and reliability or predictive value; rather, they are more appropriate criteria for an essentially personal nature, such as empathic resonance or introspective plausibility [1].

Analyzes of this nature allow a holistic look at the disturbed behavior of these patients, even though they are compatible with the vulnerability/stress model of schizophrenia and are very useful for studying the lifestyle of patients with long-term schizophrenia [2]. Many of these studies have revealed phases during which periods of apparent stabilization occur which, according to Davidson [3], result from the person's effort to find a functional sense of self, face to the dysfunction caused by psychotic symptoms. From this viewpoint in times of change throughout life, especially when self-esteem and the perception of others are at stake, schizophrenic patients have difficulties in dealing with both others and stressful situations, while their cognitive needs are increased. In these situations the recovery of stability depends on the degree of flexibility of the person, although an increase in positive symptoms often occurs as if these symptoms had a regulatory function.

From this type of interpretative analysis some theses resulted, placing on the vital structure of being the core of the basic disturbance of schizophrenia. One of these theses has been developed by Blankenburg and is summarized in the following expression: "The schizophrenic patient has lost the sense of the natural evidence of things". In other words, he has lost the sense of common sense. Now, it is precisely on this thesis that I would like to present to the reader some general considerations that can help us to look at the schizophrenic patient in a more individualized and, perhaps, more understanding way.

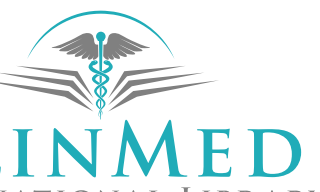

INTERNATIONAL LIBRARY

Citation: Teixeira JM (2020) Look Inside Schizophrenia and Discover Common Sense. Int Arch Nurs Health Care 6:151. doi.org/10.23937/2469-5823/1510151

Accepted: December 29, 2020: Published: December 31, 2020

Copyright: (C) 2020 Teixeira JM. This is an open-access article distributed under the terms of the Creative Commons Attribution License, which permits unrestricted use, distribution, and reproduction in any medium, provided the original author and source are credited. 
Common sense is what allows us an interpersonal understanding, as a kind of frame of reference in relation to which our daily acts, especially those involving communicational tasks, take on meaning [4]. Being what continuously defines intersubjectivity, common sense implies the knowledge of a set of "rules" of behavior, which enable us to measure and weigh the things of the world $[5,6]$ and to have a sense of the adequacy of our acts, especially those of communication, in the context of action. Based on a set of a priori axioms (axioms of everyday meaning), currently assimilated to the so-called "theory of mind" [7] or "common sense psychology" [8], the notion of common sense is linked to the notion of "reflexive schizophrenia" as a clinical concept.

This concept is based on the thesis that schizophrenic patients have lost their sense of common sense $[9,10]$, although some of them have an inflexible connection to their own principles and are continually building a "theory" [5,11-13]. Perhaps because of this Ciompi [14] suggested that the schizophrenic deficit is not cognitive, but metacognitive.

At clinical level this means that the connections between the different cognitive domains of common sense are the ones altered and not each cognitive function per se, as Naudin, et al. [15] very well pointed out. That is, common sense will operate as a frame of reference if each specific cognitive function can be related to other functions in a single specific global datum. What Ciompi [14] called affective logic or Blankenburg [12] called natural evidence but is also, in some way, linked to the cognitive concept of the theory of mind $[15,16]$. In fact, this theory ensures self-understanding and understanding of others as intentional agents, so it forms the basis of common sense, something that develops during the second year of life, at least according to Leslie [7], and that is expressed through the child's new intentional capacity and the ability to develop an understanding of the intentions of others, based on a new capacity for meta-representation. Given the disturbance of this ability in autistic children, Frith and Frith [16] suggested that in schizophrenic patients the theory of mind was also impaired, what Baron-Cohen [17] called mental blindness.

Baron-Cohen's concept is extremely useful for understanding these types of problems. This concept is rooted in a modular hypothesis called mental reading of our daily activity to attribute mental states to others. This capacity for mental reading depends on 4 specific mechanisms dedicated to (a) Detecting the intentions of others, (b) Detecting the direction of the gaze, (c) Sharing attention and (d) Elaborating a theory of mind. We can, in some way, affirm that this modular hypothesis constitutes a naturalistic basis of the Husserlian concept of intersubjectivity but, more importantly, it allows defending the hypothesis of the elective alteration of one of the parts and to overcome the non-specificity of the models that defend general functional alterations, such as Frith and Corcoran [18] did. However, the method for evidencing these elective changes will have to be based on individual assessments, not with the purpose of confirming the empirical validity of the modular hypothesis of the theory of mind, but rather to affirm its clinical value. In fact, mental blindness is important for clinical evaluation, as long as patients can make an autobiographical description of it.

From these studies, Davidson and Strauss [2] suggested that some patients were able to deal with the disease by producing a reflexive theoretical activity (what Blankenburg called the philosophizing of patients). In the words of a patient, it is possible to "learn the work of rehabilitation." In some patients this learning is done by artificially creating a theory of mind through the compilation of axioms of everyday life.

This type of studies is essential not only to complement the studies on quantitative assessment of the cognitive deficits of these patients, but also to refine the rehabilitation strategies for each individual patient. Furthermore it constitutes a comprehensive, clinically testable approach to schizophrenia based on the premise that the schizophrenic deficit is related to the process of building the sense of common sense and, in this regard, it cannot be considered a cognitive deficit, but rather a metacognitive deficit. This deficit will be partially compensated and, often, it may be masked by a rigid adherence to the axioms of common sense which, however, can allow a relatively solid, albeit distant, link to shared reality and to others.

To me, the most important in this type of approach is its implication in neuropsychological research. Supported in this phenomenological-clinical point of view, that research will greatly benefit from developing the concept of mental blindness, which, as we have seen, is very close to the phenomenological concept of loss of natural evidence. If until some time ago it was said that the comprehensive approach had stagnated and had little to say about the understanding of schizophrenia, today we have some models of approach and comprehensive research that may enable the combination of the two types of methodologies, which we have long advocated. This effort may allow for empirical research to be guided by phenomenological research, which will ultimately make it more adapted to individual patients and, to that extent, more adjusted to individualized rehabilitation strategies.

\section{References}

1. Robinson DN (1985) Philosophy of psychology. Columbia University Press, New York.

2. Davidson L, Strauss JS (1992) Sense of self in recovery from severe mental illness. Br J Med Psychol 65: 131-145.

3. Davidson L (1993) Story-telling and schizophrenia: Using narrative structure in phenomenological research. Humanistic Psychol 21: 200-220. 
4. Schutz A (1964) Collected papers. Martinus-Nijhoff, The Hague.

5. Tatossian A (1979) Phenomenologiedes psychoses. Rapport de Psychiatrie au Congrés de Psychiatrieet de Neurologie de Langue Française. LXXVII session. Paris, Masson, Angers.

6. Varela FJ, Thompson E, Rosch E (1991) The embodied mind: Cognitive science and human experience. MIT Press, Cambridge.

7. Leslie AM (1987) Pretense and representation: The origins of theory of mind. Psychol Rev 94: 412-426.

8. Dennett D (1987) The intentional stance. MIT Press, Cambridge.

9. Bovet P, Parnas J (1993) Schizophrenic delusions: A phenomenological approach. Schizophr Bull 19: 579-597.

10. McEvoy JP, Hartman M, Gottlieb D, Godwin S, Apperson LJ, et al. (1996) Common sense, insight, and neuropsychological test performance in schizophrenia patients. Schizophr Bull 22: 635-641.
11. Blankenburg W (1969) Approach to the psychopathology of common sense. Confin Psychiatr 12: 144-163.

12. Blankenburg W (1971) La perte de l'évidence naturelle. Une contribuition à la psychopathologie des schizophrénies pauci-symptomatiques (Ed. francesa de 1991). PUF, Paris.

13. Parnas J, Bovet $P$ (1991) Autism in schizophrenia revisited. Compr Psychiatry 32: 7-21.

14. Ciompi $L$ (1991) Affects as central organising and integrating factors. A new psychosocial/biological model of the psyche. Br J Psychiatry 159: 97-105.

15. Naudin J, Henry JM, Maurel-Raymondet M, Azorin JM (1997) Comment explorer la théorie de l'esprit chez les schizophrènes? Intentionnalité pulsionnelle et développement. Évol Psychiatr 62: 315-326.

16. Frith CD, Frith $U$ (1991) Elective affinities in schizophrenia and childhood autism. New Brunswick Press, New York.

17. Baron-Cohen S (1995) Mind blindness. MIT Press, Cambridge.

18. Frith CD, Corcoran R (1996) Exploring 'theory of mind' in people with schizophrenia. Psychol Med 26: 521-530. 